\title{
A posição de J. S. Mill em relação ao Estado: os casos das sociedades 'civilizadas' e das sociedades 'atrasadas' 1

\author{
Laura Valladão de Mattos ${ }^{2}$
}

\section{Resumo}

$\mathrm{O}$ artigo analisa as concepções de Mill sobre quais deveriam ser a forma de governo e o escopo de atuação do Estado na vida econômica e social. Argumenta-se que, segundo o autor, a resposta a essas indagações dependeria do tipo de sociedade em questão. Em sociedades 'atrasadas', por uma questão de imaturidade moral e intelectual da população, a forma mais adequada de governo seria o despotismo esclarecido e o escopo adequado de atuação do Estado na vida econômica e social seria bastante amplo. No caso de sociedades 'civilizadas', ao contrário, o regime político ideal seria a Democracia Representativa e o laissez-faire, em linhas gerais, seria a melhor política. Argumenta-se, ainda, que, apesar de Mill concluir que a Democracia Representativa e a liberdade econômica não seriam aplicáveis ou adequadas a todas as sociedades, estas tinham um peso importante na sua filosofia: representavam ideais a serem buscados.

Palavras-chave: Mill, John Stuart; Laissez-faire; Democracia; Desenvolvimento.

\section{Abstract}

\section{J. S. Mill's views on the State: the cases of 'civilized' and 'backward' societies}

This paper analyses J.S. Mill's conceptions on what would be the proper form of government and the proper scope of State intervention in economic life. It is argued that, for Mill, the answer depended on the type of society in question. In 'backward' societies, in which the population encountered itself in a very low state of moral and intellectual improvement, the adequate form of government would be enlightened despotism and the adequate scope of the State intervention in economic and social life very great. In 'civilized' societies, on the contrary, the ideal political regime would be the Representative Government, and laissez-faire, in general lines, the best policy. It is also argued that despite Mill's conclusion that Representative Government and economic liberty would not be applicable or adequate to every kind of society, they had a great importance on his philosophy as ideals to be aimed at.

Key words: Mill, John Stuart; Laissez-faire; Representative democracy; Development.

JEL B120.

(1) Trabalho recebido em abril de 2007 e aprovado em junho de 2007. Foi desenvolvido como parte das minhas obrigações como bolsista de Produtividade em Pesquisa do $\mathrm{CNPq}$ (Conselho Nacional de Desenvolvimento Científico e Tecnológico). Agradeço o apoio financeiro recebido. Agradeço igualmente ao Antônio Carlos Alves dos Santos e ao José Eduardo Godoy Jr. por seus valiosos comentários, que ajudaram a melhorar o trabalho.

(2) Professora da Pontifícia Universidade Católica de São Paulo, Faculdade de Economia e Administração, Departamento de Economia, São Paulo, SP, Brasil. E-mail: <lauramat@ uol.com.br>.

Economia e Sociedade, Campinas, v. 17, n. 1 (32), p. 135-155, abr. 2008. 


\section{Introdução}

J. S. Mill é conhecido por valorizar a liberdade política, individual e, mais especificamente, a liberdade econômica. E, de fato, essa fama não é injustificada. No que tange ao que ele denominava países 'civilizados' - que teriam como o exemplo mais proeminente a Inglaterra - ele claramente adotou a posição de que, como regra geral, seria desejável, por um lado, garantir aos indivíduos o máximo de participação política e liberdade de expressão possíveis e, por outro, restringir ao mínimo a interferência do Estado na vida econômica e social.

No entanto, captamos somente uma dimensão do pensamento do autor quando o colocamos como porta-voz da liberdade. Na verdade, as suas concepções sobre Estado são cheias de nuances mesmo no que se refere às nações 'avançadas', e revelam-se radicalmente diferentes quando se trata de países que se encontram em estágios de 'civilização' mais 'atrasados'. Como esse aspecto do pensamento de Mill é relativamente pouco explorado na literatura secundária, pretende-se neste artigo preencher essa lacuna e analisar a teoria de Mill sobre o Estado ressaltando a diferença de tratamento dado às nações por ele consideradas 'civilizadas' vis-à-vis as consideradas 'atrasadas'. ${ }^{3}$ Para essa análise serão adotadas basicamente duas perspectivas: (a) uma perspectiva política, que diz respeito a qual forma de governo (ou regime político) que, para o autor, seria desejável adotar em cada situação; e (b) uma perspectiva econômica (e social) que considera qual deveria ser, em cada contexto, o escopo de atuação do Estado.

Argumenta-se que, para Mill, não haveria uma regra universal sobre qual deveria ser a forma de governo ou a atuação do Estado na esfera individual, social e econômica. Dependendo da situação específica, o regime político mais adequado poderia ser despótico ou democrático e a intervenção do Estado poderia ser bastante extensa ou diminuta. O importante para Mill seria que esses fossem tais que levassem ao aprimoramento dos homens e os preparassem para a próxima etapa no caminho do desenvolvimento. Argumenta-se, ainda, que, apesar de Mill

(3) Há uma quantidade enorme de textos na literatura secundária que analisam as posições de Mill em relação ao papel do Estado em sociedades 'avançadas'. Duas obras de referência são Schwartz (1968) e Hollander (1985) que apresentam análises cuidadosas e detalhadas sobre as razões pelas quais Mill defende como regra geral o laissez-faire e sobre as exceções que ele admite a esse princípio. Outras obras a serem citadas são Kurer (1991), West ([1978], 1991), Ekelund Jr. e Tollison (1976 e [1978] 1991) e Holloway (1960). A maior parte desses artigos centra as suas análises na discussão das exceções que Mill aponta ao laissez-faire, ou seja, analisa algumas (ou todas) as funções que Mill julgava que seria pertinente o Estado assumir, como, por exemplo, no campo da pobreza, da educação, da lei da herança, da legislação sobre a terra - aspectos esses que não serão enfatizados no presente artigo. No que se refere às sociedades 'atrasadas' existem também vários textos de interesse. Podemos citar Zastoupil (1983), Sullivan (1983), Collison Black (1968 e 1953), Harris ([1964], 1991), Moir (1990), Schweinitz JR. (1984), que tratam de aspectos das posições de Mill principalmente em relação à Índia e à Irlanda (povos 'atrasados') ou ao Império Britânico de uma forma geral. No entanto, apesar de trazerem contribuições e de alguns serem intensamente utilizados, tais trabalhos não abordam especificamente a questão que será desenvolvida neste artigo. 
concluir que a Democracia Representativa e a liberdade econômica não seriam aplicáveis ou adequadas a todas as sociedades, tinham um peso importante na filosofia milliana: representavam ideais a serem buscados.

Com esse objetivo em mente, será inicialmente explicitada a relatividade histórica que Mill introduz às suas análises sobre as sociedades e sobre as instituições sociais - entre elas o Estado (seção 1); a seguir serão apresentadas as concepções do autor sobre o papel do Estado em países 'civilizados' e em países 'atrasados' (seções 2 e 3); e, por fim, serão tecidas algumas considerações sobre a filosofia social do autor.

\section{Estado e a historicidade das instituições sociais}

Uma das consequiências duradouras do afastamento de Mill em relação à filosofia de Bentham e de James Mill durante sua 'crise mental', e do contato com as idéias de autores como Carlyle, Coleridge, Comte e saint-simonianos, foi a introdução de certa historicidade à sua análise das instituições sociais. ${ }^{4}$

Além de recusar defesas 'abstratas' da democracia - obtidas através do método dedutivo (Mill, [1843], 1987, p. 77-82) -, Mill passou a recusar igualmente a tendência predominante nos economistas políticos de sua época de implicitamente tomarem a Inglaterra como referência das suas análises, e de as aplicarem, sem mediações, a outras sociedades (Mill, [1870], 1967, p. 670). Para ele, estaria cada vez mais evidente que máximas assumidas por eles como sendo princípios universais como, por exemplo, as vantagens ilimitadas do laissez-faire e da liberdade de contratos, a inviolabilidade da propriedade privada da terra, os benefícios da concorrência, a teoria do fundo de salários, a idéia de que os homens desejam riqueza, etc., talvez não fossem “(...) nem um pouco universais, mas apenas costumes ingleses (...).” (Mill, [1870], 1967, p. 671). No seu entender, estas poderiam, quando muito, ser aplicadas com alguma pertinência à Inglaterra, mas não extrapoladas para situações muito diferentes sem induzir a sérios erros. Existiriam, para ele, diferenças significativas mesmo entre as nações com um mesmo nível de desenvolvimento e extremamente marcadas entre aquelas que se encontravam em níveis diferentes de desenvolvimento - e seria crucial considerálas nas discussões sobre instituições políticas e econômicas.

(4) Mill afastou-se de análises políticas como as que atribuía a Bentham que “(...) assume[m] que os homens são iguais em todas as épocas e lugares, que eles têm as mesmas necessidades e são expostos aos mesmos males(...)" (Mill, [1833], 1969, p. 16). E também das análises dos economistas políticos que tinham a tendência de tomarem "(...) a sua experiência presente da humanidade como tendo validade universal (...)”. (Mill, [1865], 1969, p. 306). 


\subsection{Os diferentes estágios de civilização - de 'selvagens' a 'civilizados'}

A forma como Mill levou em conta essas diferenças no nível de desenvolvimento dos diferentes povos e países foi introduzindo uma classificação que posicionava as nações tendo como referência basicamente o nível atingido no que ele denomina 'processo de civilização' - o processo de desenvolvimento (capitalista) e de enriquecimento pelo qual passaram os vários países modernos da Europa (Mill, [1836], 1973, p. 45). ${ }^{5}$

Como ressalta Sullivan, “(...)[Mill] supôs que existiria uma escala de civilização facilmente disponível (readily available) segundo a qual os povos podem ser ordenados." (Sullivan, 1983, p. 610). No topo da escala estariam situados a Inglaterra e outros países modernos da Europa, e na sua base povos e nações que Mill designa 'selvagens', ou 'bárbaros'. Na verdade, o estado 'selvagem' ou 'bárbaro' não seria senão a antítese do estado 'civilizado' - o seu exato oposto (Mill, [1836], 1973, p. 46).

O estado civilizado caracterizar-se-ia por uma população densa e estabelecida, comércio, manufatura e agricultura abundantes; por um grande (e crescente) domínio sobre a natureza (Mill, [1848], 1965, p. 706); pela “(...) difusão da propriedade, da inteligência e o poder de cooperação" (Mill, [1836], 1973, p. 50); e pela existência de instituições coletivas que garantiriam o respeito às leis e proteção à pessoa e propriedade (Mill, [1836], 1973, p. 46 e Mill, [1848], 1965, p. 706).

O estado selvagem caracterizar-se-ia, ao contrário, por uma população esparsa e errante, a ausência de comércio, manufatura e mesmo agricultura, pelo pequeno domínio sobre a natureza, pela falta de leis ou de administração de justiça - a segurança e propriedade dependendo totalmente da força, da sagacidade e da coragem de cada indivíduo -, e pela diminuta cooperação e falta de vínculos dos indivíduos com a comunidade (Mill, [1836], 1973, p. 46). ${ }^{6}$

Entre esses dois extremos da escala estariam povos que já teriam saído do estágio 'bárbaro' - tendo instituições estabelecidas, leis, governos, que alcançaram algum nível de cooperação e de ação coletiva - mas que, apesar de mais aprimorados em termos institucionais e morais do que os 'selvagens', ainda não teriam alcançado o estágio de civilização mais elevado atingido pela Inglaterra e outros países avançados da época. Nesse estágio intermediário de civilização

(5) Como veremos, este processo não teria sido somente um processo de enriquecimento material, mas envolveria igualmente, apesar de não de forma homogênea, aprimoramento intelectual, moral e estético.

(6) A caracterização que Mill faz do 'selvagem' não tem embasamento histórico; como sugerido acima, ele simplesmente retrata o selvagem como a imagem invertida do 'civilizado'. À luz dos estudos antropológicos modernos, fica evidente que a descrição apresentada de 'sociedades primitivas' não é corroborada pelas evidências, principalmente no que se refere à falta de vínculo dos indivíduos com a comunidade e falta de capacidade para cooperar. 
podemos situar, por exemplo, a Índia e a Irlanda, dois países que, por razões diversas, receberam muita atenção de Mill. ${ }^{7}$

As diferenças mentais, culturais e morais seriam igualmente bastante marcantes no que concerne a esses dois extremos da escala de 'civilização'. E, também neste quesito, os 'civilizados' seriam, no entender de Mill, bastante 'superiores' aos 'bárbaros' e 'selvagens'.

O processo de civilização teria, através da introdução de instituições (o Estado sendo uma das principais), ‘educado' e 'moldado' o caráter dos homens de forma a torná-los crescentemente capazes de cooperar e atuar coletivamente (Mill, [1836], 1973, p. 49-50 e Mill, [1848], 1965, p. 708), menos autocentrados, mais capazes de simpatizar com outros (Levy; Peart, 2003, p. 20), mais previdentes, mais confiáveis, mais disciplinados, mais capazes de controlarem suas paixões, mais inteligentes, mais bem informados. Essas características teriam sido fundamentais para a obtenção do nível de riqueza prevalecente nesses países.

No entanto, apesar de o caráter humano ter sido, inequivocamente, melhorado moral e intelectualmente, o processo de civilização teria acarretado igualmente algumas perdas importantes. A introdução de um sistema de leis e de administração da justiça, ou seja, da ação coletiva para proteger os indivíduos e sua propriedade, teria feito com que os homens 'civilizados' perdessem energia de caráter e iniciativa (Mill, [1836], 1973, p. 57-59). Praticamente a única esfera que restaria para exercitar esses traços de caráter seria a esfera da busca por riqueza material (Mill, [1836], 1973, p. 56). Além disso, o peso da ação coletiva sobre a ação individual e a difusão da inteligência e do poder entre a população (que eram, para Mill, consequiências naturais do processo de civilização) estariam engendrando uma perda da individualidade, da diversidade e da originalidade dos indivíduos.

Os selvagens, por sua vez, embora possuíssem energia de caráter e independência em abundância - que, se domesticadas, representariam elementos valiosos de caráter -, não possuiriam, na visão de Mill, outras características fundamentais ao progresso, principalmente ao progresso material.

O 'selvagem' não teria disciplina e seria incapaz de empenhar-se de forma contínua em trabalhos tediosos (Mill, [1848], 1965, p. 103 e Mill, [1861], 1958, p. 31). Seria inapto à cooperação e ao agir coletivamente, uma vez que ele não teria disciplina moral suficiente para controlar as paixões e ser guiado pela razão ou por planos previamente concebidos (Mill, [1848], 1965, p. 708). Ele seria pouco desenvolvido em termos intelectuais, imprevidente, incapaz de prever o futuro e de esforçar-se para obter objetos distantes no tempo (Mill, [1848], 1965, p. 103 e Mill,

(7) Mill às vezes refere-se mesmo à Irlanda e à Índia como estados 'selvagens', 'bárbaros', outras como ainda 'não civilizados', no entanto, é evidente que ele vê uma diferença na escala de civilização alcançada pelos índios selvagens norte-americanos e pelos povos da Índia e Irlanda. 
[1848], 1965, p. 163-164). O 'selvagem' teria pouca ambição, reduzido desejo por consumir bens, e o desejo de acumular, uma das mais importantes motivações subjacentes ao aumento de riqueza, seria quase inexistente (Mill, [1848], 1965, p. 162-163). ${ }^{8}$ Além disso, os povos menos desenvolvidos seriam carentes de autocontrole (Mill, [1836], 1973, p. 48-49), e em especial no que se refere ao controle sobre a sua reprodução (Mill, [1848], 1965, p. 157). A questão populacional não representaria uma dificuldade nos primeiros estágios de civilização onde a população é escassa, no entanto, em países subdesenvolvidos com grande densidade populacional (como a Irlanda), seria um problema sério, pois Mill, como malthusiano que era, via no crescimento desordenado da população a principal causa da pobreza (Mill, [1848], 1965, p. 367-368). ${ }^{9}$

No cômputo geral, como mencionamos, é evidente que Mill considerava os povos 'civilizados' muito superiores aos 'atrasados' no que concerne não só à sua forma de organização como também às suas qualidades morais, intelectuais e estéticas. Todavia, apesar de Mill ter essa convicção, é importante salientar que, nessa avaliação, não entravam elementos de cunho racial. Ele explicitamente rejeitou as interpretações que associavam o atraso econômico, social, moral e político a atributos raciais, considerando vulgar “(...) atribuir a diversidade de conduta e caráter às diferenças naturais inerentes." (Mill, [1848], 1965, p. 319). Para ele, as características dos homens seriam basicamente resultados dos arranjos institucionais existentes. ${ }^{10}$ Como aponta Sullivan, em Mill, a falta de civilização “(...) não era uma característica inata ou genética [de um povo]; era o resultado da história e poderia (...) ser remediado pela história(...)" (Sullivan, 1983, p. 610). Se instituições adequadas fossem adotadas, todos os povos poderiam, em última instância, tornar-se 'civilizados' - e era essa justamente a meta buscada por Mill.

Ainda assim, entendemos que o tratamento que Mill concede aos 'selvagens' vis-à-vis os povos 'civilizados' é preconceituoso e culturalmente viesado por valores europeus. No entanto, é necessário lembrar que essa era uma visão comum no século XIX, e que Mill, tal como a maior parte dos homens, era prisioneiro de alguns - mas não de todos - preconceitos de sua época.

De qualquer forma, insatisfatórias ou não, as suas concepções sobre as diferenças existentes entre as nações e os povos influenciaram muito a sua visão sobre o papel que o Estado deveria desempenhar nos diferentes tipos de

(8) A ausência dessa motivação relacionar-se-ia, no entender de Mill, às já citadas incapacidade de se esforçar por objetos distantes no tempo e falta de interesses pelos outros (Mill, [1848], 1965, p. 163-164), e à falta de segurança em relação à pessoa e à propriedade (Mill, [1848], 1965, p. 163).

(9) Para Mill, esses traços do caráter do selvagem seriam grandes impedimentos ao avanço da riqueza (Mill, [1861], 1958, p. 31; Mill, [1848], 1965, p. 103-104, 164, 708).

(10) “(...) Na filosofia de Mill, as influências boas e ruins da educação, legislação, e circunstâncias sociais tinham 'eficiência imensamente maior do que raça ou clima ou os dois combinados' na formação do caráter nacional (...)” (Harris, [1964], 1991, p. 222). Ver também Mattos (1998, p. 25-27). 
organização social. Sem levá-las em conta chegaríamos, quando muito, a um entendimento bastante incompleto das posições do autor sobre essa questão.

\subsection{A relatividade histórica das instituições: a teoria sobre o Estado}

Em conformidade com a visão de que a consideração das diferenças culturais e de desenvolvimento seria importante nas discussões sobre instituições e políticas, Mill não advogou uma receita universal, válida para qualquer sociedade, no que concerne ao Estado. Segundo ele, “(...) a mesma instituição não se adequará a duas nações em diferentes estágios de civilização mais do que a mesma lição a crianças de idades diferentes." (Mill, [1833], 1969, p. 16). Diferentes sociedades demandariam diferentes formas de governo e diferentes graus de intervenção do Estado na vida econômica e social.

Mill considerava fundamental que as formas de organização e de atuação do Estado - uma das principais instituições de educação nacional de um povo (Mill, [1833], 1969, p. 16 e Mill, [1861], 1958, p. 30) - fossem, por um lado, adaptadas ao nível de educação moral e intelectual já existente e, por outro, estimulassem nos homens aquelas características que se faziam mais necessárias à continuidade do progresso social (Mill, [1861], 1958, p. 25-26, 28). O modo de atuação do Estado teria que ser tal a 'ensinar' lições que a população, por um lado, conseguisse assimilar e, por outro, necessitasse aprender. ${ }^{11}$ Uma vez que os povos tinham, no seu entender, necessidades e deficiências variadas, variadas também teriam que ser não só as 'lições' ministradas, como o modo de ministrá-las.

Não existiria, assim, uma forma de governo (ou regime político) ou um grau de intervenção estatal 'corretos' independentemente do contexto histórico. $\mathrm{O}$ Estado, para ser adequado, deveria afetar positivamente as pessoas de modo a favorecer o "(...) próximo passo que é necessário darem de forma a elevarem-se a um nível superior.” (Mill, [1861], 1958, p. 30). E não interessaria somente o próximo passo, mas também a seqüência de passos que viriam a seguir (Mill, [1861], 1958, p. 33).

Neste contexto, é interessante ressaltar que os próprios elementos que constituiriam o progresso social também variariam em se tratando de sociedades em etapas de desenvolvimento diferentes.

Em sociedades 'avançadas' (e ricas) como a Inglaterra, o progresso social significaria, eventualmente, até a redução do crescimento econômico e o incentivo a motivações 'mais elevadas' do que o desejo por riqueza (Mill, [1848], 1965,

(11) "A primeira questão a respeito de qualquer instituição política é o quanto ela tende a promover nos membros da comunidade as várias qualidades morais e intelectuais desejáveis(...)” (Mill, [1861], 1958, p. 25). 
p. 753-757). ${ }^{12}$ Nelas, os grandes empecilhos ao progresso seriam, como vimos, a falta de energia de caráter reinante (ou sua concentração na esfera da busca pela riqueza), a crescente uniformidade de condições e de caracteres e o crescente peso das massas sobre os indivíduos. Essas tendências, como vimos, estariam colocando em risco a iniciativa, a individualidade, a originalidade, e diversidade de caracteres - elementos que Mill julgava fundamentais para o progresso nessas sociedades 'avançadas' (Mill, [1848], 1965, p. 940).

Nas sociedades 'selvagens', progresso significaria basicamente criar as condições morais e intelectuais para que o crescimento econômico pudesse ocorrer. Os grandes empecilhos ao progresso seriam, conforme mencionado, a preguiça, a falta de confiabilidade, o baixo desenvolvimento da inteligência, a imprevidência, a carência de disciplina ou de ambição e a falta de desejo por riqueza.

Como as deficiências e os obstáculos ao progresso e, portanto, as influências que o Estado deveria exercer sobre os homens seriam de naturezas distintas nas diferentes sociedades, a forma e a atuação do Estado também deveriam ser. Coerentemente com isso, Mill apresenta visões radicalmente diferentes sobre quais deveriam ser as formas de governo e os graus de intervenção do Estado em sociedades 'avançadas' e em sociedades 'atrasadas'. Trataremos primeiramente das suas opiniões no que tange ao papel do Estado em sociedades 'civilizadas', para, posteriormente, tratarmos da sua visão sobre as nações 'selvagens' ou 'atrasadas'.

\section{Estados 'avançados': a liberdade como melhor garantia para o progresso}

No que se refere aos países 'avançados', Mill sustenta que as liberdades política, individual e econômica seriam as melhores garantias de progresso social. As suas famosas defesas da Democracia Representativa na obra Considerações sobre o Governo Representativo, da liberdade e da individualidade no ensaio Sobre a Liberdade, e do princípio da não-intervenção nos seus Princípios de Economia Política, aplicavam-se a essas nações que já teriam alcançado um nível 'adiantado' no processo de civilização. No cerne da defesa de Mill dessas instituições está, no nosso entender, a idéia de que elas contrabalanceariam os

(12) Como coloca Harris, na concepção de Mill, “(...) progresso significava desenvolvimento da capacidade para auto-comando (self-directio), a socialização dos atributos humanos, e o melhoramento qualitativo dos objetos dos desejos dos homens. De acordo com isso, progresso consistia não principalmente de melhoramento material, mas de cultivo moral-estético (...)" (Harris, 1956, p. 173). Holloway enfatiza também a importância dada por Mill ao desenvolvimento do indivíduo: "Mill adotou como valor central o livre desenvolvimento da personalidade individual e a mais completa realização das suas capacidades. Para ele este era tanto o produto final como a condição central (prime condition) da civilização" (Holloway, 1960, p. 390). Na Inglaterra, seria mais importante distribuir melhor a riqueza do que continuar a empenhar-se obcecadamente em aumentá-la. 
efeitos perversos do 'processo de civilização' e que promoveriam os traços de caráter necessários ao progresso nessas sociedades.

\subsection{A defesa da democracia representativa}

A discussão já empreendida sobre a relatividade histórica das instituições deixa claro que, para Mill, não haveria uma forma de governo adequada a todos os tipos de sociedades. No entanto, ele julgava ser possível refletir sobre qual seria o regime político 'ideal', utilizando o método de comparar as diferentes formas de governo em termos de suas conseqüências para o melhoramento humano, supondo existirem as condições necessárias para seu funcionamento adequado (Mill, [1861], 1958, p. 35): “A forma de governo idealmente melhor (...)[é] uma na qual, em circunstâncias em que seja praticável e adequada, é acompanhada do maior montante de consequiências benéficas, imediatas e prospectivas" (Mill, [1861], 1958 , p. 43). E, no seu entender, essa forma ideal seria a Democracia Representativa.

Todavia, Mill não defendia qualquer modelo de democracia, mas a superioridade de um tipo específico no qual se atribuísse uma ponderação maior aos votos daqueles que tinham mais conhecimento e escolaridade e no qual fosse garantida voz às minorias (Mill, [1861], 1958, p. 136-142 e Mill, [1861], 1958, p. 102-118). ${ }^{13}$ Influenciado por De Tocqueville, Mill temia que a democracia pudesse transformar-se em uma ditadura da maioria sobre as minorias e acabasse por reforçar a tendência à perda de individualidade, diversidade e originalidade, já forte em sua época (Mill, [1861], 1958, p. 94 e 117, Mill, [1848], 1965, p. 939940). No entanto, introduzidas as salvaguardas necessárias, a Democracia Representativa seria, no seu entender, 'idealmente' a melhor forma de governo.

Ela, por um lado, garantiria que os direitos e os interesses das pessoas não fossem negligenciados - estes “(...) só estão protegidos (...) quando a pessoa interessada é ela mesma capaz, e está habitualmente disposta, a lutar por eles (...)" (Mill, [1861], 1958, p. 43) - e, por outro, patrocinaria o desenvolvimento das faculdades humanas. Este segundo argumento tem um peso bastante grande na defesa que o autor faz dessa instituição.

Ao participarem da vida política, os homens colocariam as suas energias em ação e organizar-se-iam para fazer as coisas necessárias a si mesmos e ao seu país. Isso teria impactos muito mais positivos, tanto sobre o intelecto como sobre o caráter humano, do que a postura passiva de esperar que outros (o Estado)

(13) Ver também Holloway (1960, p. 393) e Hamburger (1982, p. xx). Para uma descrição detalhada das posições políticas de Mill no que concerne à Inglaterra, em especial à sua relação com os diversos partidos existentes e à sua defesa da Reforma Parlamentar, ver Hamburger (1982). 
organizassem e realizassem as coisas por eles. ${ }^{14}$ Segundo Mill “(...) o tipo de caráter passivo é favorecido pelo governo de um ou de poucos, e o caráter do tipo ativo e auto-dependente (self-helping) pelo governo de muitos" (Mill, [1861], 1958, p. 52). A democracia, dada a participação política que propicia, estimularia a formação de cidadãos com caráter ativo e energético - traços de caráter que Mill considerava, como vimos, essencial incentivar.

Essa participação em assuntos sociais teria, ademais, a vantagem de alargar a visão dos indivíduos, cujas tarefas do cotidiano em geral não os levavam além do seu auto-interesse estreito, e de permitir o contato com pessoas mais ilustradas (Mill, [1861], 1958, p. 53). Além disso, fornecer ao indivíduo a oportunidade de fazer algo pelo público ajudaria na sua educação prática e melhoraria o seu caráter, além de torná-lo mais envolvido emocionalmente com a sua comunidade (idem). Para Mill, o “(...) alimento dos sentimentos é a ação (...) Deixe uma pessoa não ter nada para fazer pelo seu país, e ela não irá se importar com ele (care for it)" (Mill, [1861], 1958, p. 38).

Assim, a Democracia Representativa tenderia a corrigir algumas das deficiências observadas nos povos 'civilizados' e a estimular na população traços de caráter positivos - favorecendo, assim, o avanço dessas sociedades.

Todavia, apesar de considerar a Democracia Representativa a forma ideal de governo, esta só seria viável e adequada caso o povo em questão tivesse inclinação a aceitá-la, caso tivesse disposição para executar aquilo que é necessário para preservá-la, e caso possuísse capacidade e aptidão para desempenhar as funções e deveres que essa forma de governo impõe (Mill, [1861], 1958, p. 55-56). No entanto, essas condições exigiriam qualidades morais e intelectuais existentes unicamente entre os povos 'mais avançados' na escala da civilização. Como veremos, os povos 'selvagens' ou 'atrasados' não estariam, segundo o autor, preparados ou maduros para o autogoverno, e teriam pouco a ganhar com a democracia (Mill, [1861], 1958, p. 56-62). Assim, outras formas de governo 'idealmente' inferiores, no entanto mais adequadas às condições morais e intelectuais desses povos, precisariam ser adotadas.

\subsection{A defesa da liberdade econômica}

No que se refere ao escopo de atuação do Estado, Mill defendeu como regra geral para os países 'avançados' o princípio da não-interferência. Nas suas palavras: "O laisser-faire (...) deve ser a prática geral; todo afastamento em

(14) Para Mill, a "[i]niciativa, o desejo de continuar se movendo, de tentar e conseguir novas coisas para nosso próprio benefício e para benefício dos outros, é o pai do talento especulativo e muito mais ainda do talento prático" (Mill, [1861], 1958, p. 48). 
relação a ele, a não ser que exigido por um grande bem, é um mal certo" (Mill, [1848], 1965, p. 945).

É bom esclarecer, entretanto, que ao defender o laissez-faire como uma prática geral, Mill estava longe de advogar uma ausência do Estado ou de endossar um Estado Mínimo (apenas defensor da ordem e da propriedade). Ele estabelece nos Princípios uma distinção entre intervenções 'necessárias' e 'facultativas' do Estado (Mill, [1848], 1965, p. 800) e coloca dentre as intervenções 'necessárias', que seriam “(...) ou inseparáveis da idéia de um governo, ou são habitualmente exercidas sem objeções por todos os governos” (idem), uma extensa lista de funções como a de arrecadar impostos, estabelecer leis de herança; estabelecer leis sobre a propriedade de reservas naturais da terra; estabelecer e manter os contratos, manter a justiça, cunhar moeda, fornecer padrão de medidas e pesos, limpar as ruas, construir faróis, financiar pesquisas científicas, entre outras coisas (Mill, [1848], 1965, p. 800-804). Essas funções seriam atribuições do Estado e, portanto, nelas ele deveria atuar. O princípio da não-interferência aplicar-se-ia basicamente às intervenções 'facultativas' (Harris, 1956, p. 159 e Schwartz, 1968, p. 177), ou seja, àquelas cuja “(...) conveniência de seu exercício não equivale a uma necessidade" (Mill, [1848], 1965, p. 800). Entre essas intervenções 'facultativas' estariam as intervenções do Estado na economia - no campo da produção de riqueza e do comércio - e em outras esferas da vida social. ${ }^{15}$

O fundamento dessa posição a favor da não-interferência é a crença de Mill de que, de uma forma geral, a política de deixar o máximo possível ao encargo dos indivíduos da sociedade produziria resultados mais eficientes em termos econômicos e mais favoráveis em termos de aperfeiçoamento humano, do que aquela de jogar para o Estado a responsabilidade pelos principais aspectos da vida econômica e social.

No que se refere à eficiência econômica, Mill acreditava que “(...) como regra geral, os assuntos da vida são realizados de uma forma melhor quando aqueles que têm um interesse imediato neles são deixados livres para escolher o seu próprio caminho (...)" (Mill, [1848], 1965, p. 946). E a iniciativa privada renderia resultados superiores aos obtidos pelo empreendimento público pelo fato

(15) Mesmo no que se refere às intervenções facultativas, Mill apontou inúmeras exceções à regra da pertinência da adoção do laissez-faire no que concerne a sociedades 'civilizadas'. Em alguns setores do campo social, a livre-iniciativa individual não geraria bons resultados, por exemplo, na educação, no trato com os pobres, requerendo, portanto, a intervenção do Estado (Mill, [1848], 947-950 e 960-967; ver também Kurer (1991); West ([1978], 1991); Ekelund Jr. e Tollison (1976, [1978], 1991). No campo econômico, em inúmeras circunstâncias, a intervenção estatal se faria necessária em nome da eficiência. Podemos citar como exemplo o caso dos monopólios naturais (Mill, [1848], 1965, p. 955-956); de bens que, apesar de importantes, não geram lucro capaz de justificar a sua produção (Mill, [1848], 1965, p. 968), e da indústria nascente (Mill, [1848], 1965, p. 918). Para Schwartz (1968, p. 171), o tratamento dessas exceções foi uma das inovações teóricas mais interessantes de Mill no que diz respeito à economia. 
de os indivíduos terem, nesta primeira forma de organização, um interesse mais direto nos resultados (Mill, [1848], 1965, p. 942 e Mill, [1859], 2000, p. 165).

Além disso, como Mill considerava que, na maior parte dos casos, os indivíduos seriam “(...) juízes melhores do que o governo sobre os meios de alcançar o fim específico a que eles visam (...)” (Mill, [1848], 1965, p. 946), nada mais natural do que deixá-los buscar os seus objetivos com o mínimo de interferência possível. Essa forma de proceder aumentaria, ademais, a probabilidade de inovação tecnológica. O Estado, no entender de Mill, tenderia a realizar as coisas de uma forma uniforme, enquanto na existência de competição entre diversas firmas conduzidas por indivíduos com histórias e talentos diversos, os mesmos fins seriam buscados utilizando meios diferentes (Mill, [1848], 1965, p. 942).

Esses são, resumidamente, os principais argumentos econômicos apresentados por Mill na sua defesa do laissez-faire. No entanto, entendemos que, mais importantes do que esses, são os argumentos filosóficos, que guardam semelhança com aqueles utilizados para defender a Democracia Representativa, e relacionam-se com os efeitos benéficos da adoção do princípio da nãointerferência sobre o melhoramento humano. Este incentivaria aquelas características humanas cuja falta estaria sendo um obstáculo ao progresso nas sociedades 'civilizadas'.

A restrição das atribuições do Estado seria fundamental para a preservação da liberdade individual - elemento considerado por Mill essencial para o desenvolvimento do homem 'civilizado' (Mill, [1848], 1965, p. 938 e Hollander, 1985, p. 691). Ele acreditava que “(...) todo aumento das funções delegadas ao governo é um aumento em seu poder, tanto na forma de autoridade, como, principalmente, na forma de influência indireta (...)" (Mill, [1848], 1965, p. 939) o que não era visto com bons olhos. No limite, se todas as perspectivas de emprego e de ascensão social estivessem diretamente atreladas às decisões do Estado, independentemente da forma constitucional assumida por este, haveria despotismo (Mill, [1859], 2000, p. 167 e Schwartz, 1968, p. 178-179).

Ademais, como ressaltado anteriormente, o ato de tentar resolver não só problemas autoconcernentes, como também assuntos comunitários, através da união não tutelada dos esforços individuais, seria uma fonte muito poderosa de educação popular (Mill, [1848], 1965, p. 942-944 e Mill, [1859], 2000, p. 165166). ${ }^{16}$ Demandaria a utilização das energias de caráter - e, portanto, ajudaria a promovê-las -, a inteligência, a prudência, a responsabilidade e, principalmente, a autonomia dos diversos indivíduos da sociedade. Ao contrário, retirar dos indivíduos (e jogar para o Estado) a necessidade de enfrentar, por seus próprios

(16) Este ponto é frisado por Hollander (1985, p. 690). 
meios e iniciativas, as dificuldades envolvidas na administração de seus interesses pessoais e dos assuntos comunitários, reforçaria, também na esfera econômica, a passividade e o relaxamento da energia de caráter da população - características que Mill julgava essencial combater. O Estado deveria, portanto, não só ceder espaço, como estimular ao máximo, as iniciativas espontâneas dos indivíduos, tanto na condução de seus próprios interesses, quanto na administração através de cooperação voluntária dos interesses conjuntos (Mill, [1848], 1965, p. 944).

Essa questão do aprimoramento humano era tão importante que Mill preferiria deixar as tarefas a cargo da iniciativa privada mesmo em casos de o Estado ser capaz de executá-las de forma mais eficiente (Mill, [1848], 1965, p. $942-943$ e Harris, 1956, p. 161).

O modo de atuação do Estado na vida econômica e social em sociedades avançadas deveria ser, então, restringir ao máximo a sua interferência, deixando a cargo dos indivíduos a organização, produção e execução da maior parte dos bens e serviços necessários. O laissez-faire reforçaria a liberdade individual, a energia de caráter, a individualidade, características muito prezadas por Mill e que precisariam ser cultivadas nos povos 'civilizados' para que o progresso social pudesse ter continuidade.

No entanto, obviamente também essa recomendação no que se refere à atuação do Estado não teria validade universal. Como aponta Schwartz, estava claro para Mill que “(...) regras como o laissez-faire não podiam ser absolutas, e sim haviam de ser consideradas em relação ao tempo e ao espaço (...).” (Schwartz, 1968, p. 169). Como veremos, tal como a Democracia Representativa, essa forma de atuação do Estado na economia seria adequada apenas aos povos que já teriam atingido níveis de desenvolvimento semelhantes aos da Inglaterra, ou seja, os estágios 'mais avançados' de civilização.

\section{O papel do Estado em países 'atrasados' ou 'selvagens'}

Vimos que, no que se refere aos países 'avançados' ou 'civilizados', a liberdade nos vários âmbitos da vida política, social e econômica era vista como a melhor garantia para o progresso. No entanto, Mill deixa claro que a liberdade, como um princípio, “(...) se aplica unicamente a seres humanos que atingiram a maturidade de suas faculdades (...)” (Mill, [1859], 2000, p. 18), o que não seria o caso das populações em países 'atrasados' que, segundo ele, encontrar-se-iam “(...) ainda em [sua] menoridade” (idem). Quando se trata de países 'selvagens' ou 'atrasados', a sua visão sobre formas de governo e de atuação do Estado revela-se radicalmente diferente daquela defendida para as nações 'civilizadas'. Essa posição nos parece consistente com a sua teoria das instituições. Uma vez que, no seu entender, as necessidades e deficiências das populações 'selvagens' eram 
radicalmente diferentes daquelas dos povos 'avançados', deveria variar “(...) igualmente, o tipo de influência social necessária para levar a comunidade em direção ao próximo estágio de seu progresso" (Mill, [1833], 1969, p. 16).

Veremos que, no que concerne às formas de governo, Mill julgava que os povos 'atrasados' seriam incapazes de se autogovernar, e que, portanto, outras formas de governo (autoritárias ou paternalistas) seriam mais adequadas às suas necessidades do que a democrática. ${ }^{17} \mathrm{~A}$ própria necessidade de respeito à autonomia dessas nações é colocada em questão. Para Mill, o progresso desses povos poderia requerer que eles fossem conquistados e governados (contra sua vontade) por nações 'mais civilizadas'.

No que se refere à atuação econômica do Estado, veremos que Mill admite que uma política de laissez-faire dificilmente poderia (ou deveria) ser adotada em países 'selvagens' ou 'pouco desenvolvidos'. Dependendo do nível de 'atraso', a intervenção do Estado poderia ter que se estender até ocupar quase a totalidade da vida econômica e social.

\subsection{A incapacidade para o autogoverno: a defesa do despotismo e imperialismo}

Como mencionado, para Mill, a forma de governo deveria ser compatível com o nível de aprimoramento humano prevalecente na sociedade e deveria contribuir para sanar as principais deficiências da população preparando-a para dar um próximo passo rumo ao progresso. E dadas as características dos 'selvagens' ou dos povos 'atrasados', a questão da liberdade, tão importante no contexto das sociedades 'adiantadas', não constitui, para Mill, um ingrediente essencial ao progresso podendo vir até a ser um entrave. No caso de sociedades muito pouco evoluídas nas quais a total falta de disciplina e a incapacidade para empenho regular no trabalho obstam o progresso, “(...) até mesmo a escravidão, ao fornecer um início para a vida industrial e ao forçá-la como a ocupação exclusiva da porção mais numerosa da comunidade, pode acelerar a transição para uma liberdade melhor do que aquela de brigar e rapinar (...)" (Mill, [1861], 1958, p. 31). ${ }^{18}$ Assim, inclusive a completa ausência de liberdade poderia ser tolerada contanto que levasse a população a superar os principais obstáculos que atravancavam o progresso social. Do mesmo modo, governos despóticos ou paternalistas rechaçados com veemência no caso da Inglaterra e outros países 'avançados' - são vistos como alternativas a serem consideradas no caso dos 'selvagens'. Para Mill, “(...) [o] despotismo é um modo legítimo de governo para tratar com bárbaros desde que a finalidade seja aprimorá-los e os meios realmente se justifiquem para realizar tal fim" (Mill, [1859], 2000, p. 18, ênfase adicionada). A ressalva feita por

(17) Ver Moir (1990, p. xlii).

(18) Mill rejeita, no entanto, de forma peremptória, a escravatura para qualquer povo que não seja totalmente bárbaro (Mill, [1861], 1958, p. 31). 
ele é fundamental para compreensão de sua posição. O objetivo do governo teria que ser melhorar os homens, e os meios empregados teriam que ser aqueles necessários e eficazes para atingir essa finalidade - caso contrário, seria ilegítimo.

Apesar de o despotismo 'esclarecido' ser encarado como a forma mais adequada de lidar com populações 'atrasadas', Mill tinha dúvidas sobre se esse despotismo poderia ser exercido com competência por indivíduos do próprio país. O despotismo nativo era visto como sendo, em geral, instável e inferior no seu desempenho ao despotismo exercido por governantes de uma nação mais 'civilizada' (Mill, [1861], 1958, p. 257; Mill, [1861], 1958, p. 64 e Harris, [1964], 1991, p. 212). E isso abre espaço para a sua defesa do imperialismo - em especial do imperialismo inglês.

Embora advogasse na esfera das relações internacionais a política de nãointervenção em assuntos internos de outros países, Mill sustentou que essa regra só valeria para as relações entre nações 'civilizadas', não devendo pautar o relacionamento entre essas nações e as nações 'bárbaras' ou 'atrasadas' (Mill, [1859], 1973, p. 377). ${ }^{19}$

As nações mais 'civilizadas' poderiam legitimamente conquistar e subjugar as 'bárbaras' uma vez que estas não teriam ultrapassado “(...) o período durante o qual é, provavelmente, para seu benefício que sejam conquistados e mantidos em submissão por estrangeiros" (Mill, [1859], 1973, p. 377, ênfase adicionada). ${ }^{20}$ Não que Mill não admitisse que vantagens pudessem advir para os países civilizados da manutenção de um império, mas a legitimidade deste dependeria dos benefícios gerados para os povos dominados. Caso os governantes dos países 'mais civilizadas' não se preocupassem com o aprimoramento do povo subjugado, eles estariam agindo como “(...) usurpadores egoístas (...)” (Mill, [1861], 1958, p. 257), e seriam “(...) culpados de negligência em relação a mais alta confiança moral que pode ser incumbida a uma nação(...)” (idem).

\subsection{A atuação do Estado e o desenvolvimento social e econômico}

O nível de desenvolvimento moral e intelectual do povo teria implicações importantes também no que se refere à forma e ao escopo de atuação do Estado na vida econômica e social em geral (Mill, [1861], 1958, p. 16). E aqui, novamente, a preocupação do autor com o caráter educativo das instituições econômicas e sociais ganha relevo, e uma função importante do Estado seria a de implementar arranjos adequados à superação do subdesenvolvimento. Haveria necessidade de

(19) Para a visão de Mill em relação a relações internacionais, ver Mill ([1859], 1973), Miller (1961) e Sullivan (1983).

(20) Ver, no mesmo sentido, Mill ([1861], 1958, p. 64). Ver também Miller (1961, p. 508-509). 
criar novas regulamentações e hábitos que fornecessem um 'pano de fundo' e os incentivos adequados para o funcionamento de uma economia de mercado. ${ }^{21}$

O Estado deveria garantir “(...) uma segurança mais completa da propriedade" (Mill, [1848], 1965, p. 186) - cuja falta seria um dos fatores que levariam a um reduzido desejo de acumular característico de povos 'atrasados' - e cobrar impostos moderados (idem):

Um dos mais infalíveis efeitos deste aumento de segurança é um grande aumento tanto na produção como na acumulação. Industriosidade e frugalidade não podem existir onde não há uma probabilidade preponderante de que aqueles que trabalham e poupam poderão aproveitar [seus frutos] (...) [trabalho e abstinência] não são à prova de um alto grau de incerteza. $\mathrm{O}$ governo pode ficar com uma parte; mas deve existir a garantia de que não interferirá (...) com o restante (Mill, [1848], 1965, p. 707).

Deveria igualmente redefinir os direitos de propriedade dos recursos naturais, em particular, da terra. ${ }^{22}$ Para Mill seria importante determinar esses direitos de forma a garantir “(...) uma posse de terra (tenure of land) mais permanente e mais vantajosa, assegurando ao agricultor tanto quanto possível os benefícios integrais do empenho (industry), da habilidade e da economia que ele venha a exercer (...)" (Mill, [1848], 1965, p. 186). Isso, por si só, resultaria em um enorme ganho de produtividade do trabalho (Mill, [1848], 1965, p. 183), bastante necessário nos países 'atrasados'.

Deveria também permitir e promover o comércio com outros países mais desenvolvidos. Um impedimento ao trabalho regular e à acumulação de riqueza em países atrasados seria a falta de vontade de consumir. Nesses casos, seria necessário o Estado estimular novos objetos de desejo, e o comércio externo, ao tornar conhecidos e acessíveis novos produtos, cumpriria esse importante papel. Isso poderia funcionar, segundo Mill, “(...) como uma espécie de revolução industrial num país cujos recursos eram previamente não desenvolvidos por falta de energia e ambição no povo (...)" (Mill, [1848], 1965, p. 593-594), uma vez que estimularia este, antes sem incentivo ao empenho, “(...) a trabalhar mais duramente de forma a conseguir a satisfação de seus novos gostos, e até economizar e acumular capital, para uma satisfação ainda mais completa destes gostos no futuro" (Mill, [1848], 1965, p. 593-594). ${ }^{23}$

(21) Como aponta Sullivan, para Mill “(...) os arranjos econômicos das sociedades em desenvolvimento eram influências educativas e civilizadoras mais cruciais do que as instituições políticas ou de educação formal (...)" (Sullivan, 1983, p. 614).

(22) A questão da terra foi talvez o ponto que Mill mais enfatizou quando tratou concretamente da questão do desenvolvimento de países como a Irlanda e a Índia - dois países sobre os quais ele refletiu muito, e que ajudaram a moldar a visão que ele passou a ter a respeito de países 'atrasados'.

(23) Ver, também, Mill ([1848], 1965, p. 104). 
Além disso, seria importante o estímulo à introdução de tecnologia de países mais avançados e à importação de capitais externos, que fariam com que o crescimento da produção não dependesse apenas da (exígua) poupança dos habitantes. Os novos capitalistas serviriam também de exemplo e estimulariam o esforço do povo nativo ao "(...) criar neles novas necessidades, um aumento da ambição, e uma maior preocupação com o futuro" (Mill, [1848], 1965, p. 186-187).

Outro campo que ganha destaque na análise de Mill é a educação formal. Para ele, seria necessário que o Estado patrocinasse a educação (que incluiria familiarização com a cultura ocidental) de modo a melhorar o nível médio de inteligência desses povos 'atrasados', e combater superstições e hábitos não condizentes com o desenvolvimento da riqueza (Mill, [1848], 1965, p. 186-187).

De uma forma geral, Mill acreditava que as intervenções estatais seriam também "(...) bem mais extensas em um estado atrasado do que em um estado avançado" (Mill, [1861], 1958, p. 16). Na verdade, Mill não estabelece qualquer limite a priori para a intervenção - esta seria, segundo ele, uma questão impossível de ser resolvida com base em princípios abstratos. A intervenção justificar-se-ia nos casos em que a utilidade fosse muito grande e nas sociedades 'atrasadas' esses casos eram inúmeros ${ }^{24}$ :

(...) Nas circunstâncias específicas de uma determinada época ou nação, dificilmente há alguma coisa realmente importante para o interesse geral que não possa ser desejável, ou até mesmo necessário que o governo assuma (...) (Mill, [1848], 1965, p. 970).

O Estado teria que atuar em diversos campos da vida econômica e, por vezes, prover a sociedade de quase todos os bens para cuja produção fosse necessário um volume maior de recursos e a cooperação:

Em muitas partes do mundo, as pessoas não conseguem fazer nada por elas mesmas que requeira grandes meios e ação conjunta: todas estas coisas são deixadas por fazer (left undone) a não ser que o Estado as realize (Mill, [1848], 1965, p. 971). ${ }^{25}$

Todavia, seja no caso de uma administração despótica, seja no caso de uma intervenção extensa do Estado no campo dos assuntos econômicos e sociais, Mill acreditava que as funções assumidas pelo Estado por conta da falta de preparo, maturidade, ou capacidade do público deveriam ser executadas “(...) de

(24) Como coloca Schwartz, utilizando a terminologia de Bentham, para Mill “(...) quanto mais curta fosse a lista de sponte acta por parte dos cidadãos, mais larga havia de ser a agenda por parte do Estado" (Schwartz, 1968, p. 195).

(25) Ver, também, Mill ([1848], 1965, p. 970). Collison Black (1968, p. 331) afirma que Mill via que países subdesenvolvidos como a Índia, e em menor grau a Irlanda, não possuíam infra-estrutura adequada ao desenvolvimento, seja em termos de estradas, canais, pontes e que considerava importante que o Estado os suprisse. 
tal maneira a não aumentar e perpetuar, mas a corrigir, essa incapacidade" (idem). A ação deveria ser sempre no sentido de estimular a iniciativa individual:

Um bom governo fornecerá todo o auxílio de tal modo a encorajar e nutrir qualquer rudimento de espírito de esforço individual que possa achar (...) O auxílio governamental (...) deve ser dado de forma a ser, na medida do possível, um curso de educação do povo na arte de realizar grandes objetivos através da energia individual e da cooperação voluntária (Mill, [1848], 1965, p. 971).

\section{Considerações finais}

Esta análise sobre a posição de Mill em relação ao papel do Estado em diferentes tipos de sociedades joga luz sobre vários aspectos que consideramos interessantes do pensamento do autor.

Revela, em primeiro lugar, o seu relativismo no que concerne às instituições políticas e econômicas. Vimos que povos situados em pontos diferentes da 'escala' da civilização necessitariam de instituições diferentes. Para povos desenvolvidos a Democracia Representativa, a liberdade de expressão e ação e o laissez-faire pareciam ao autor ser as instituições mais apropriadas à garantia do progresso. Já no caso dos povos 'atrasados' ou 'bárbaros' o despotismo político (interno ou estrangeiro) e a intervenção intensa na vida econômica e social eram considerados mais adequados. Assim, consideramos equivocado situar Mill - como fizeram os críticos da escola histórica e de outras correntes, e como fazem alguns comentadores atuais - entre os economistas que consideravam os princípios desta ciência universalmente válidos, e que empreendiam uma análise aistórica sem atentar para as especificidades locais.

Joga luz também sobre a posição de Mill em relação ao imperialismo inglês. À primeira vista poderia parecer uma incoerência o fato de Mill, o arauto da liberdade e da democracia na Inglaterra, ter sido durante 35 anos um importante funcionário da Companhia das Índias Orientais (East India Company) - que era responsável pela administração (despótica) dos territórios ingleses na Índia. ${ }^{26}$ No entanto, quando analisamos a sua teoria sobre o Estado, essa suposta incoerência desaparece. As bases dessa teoria podem ser viesadas e preconceituosas, mas à luz dela o fato de Mill usar 'dois pesos e duas medidas' quando trata de países 'civilizados' (como a Inglaterra) e de países 'atrasados' (como a Índia ou a Irlanda), passa a ser totalmente natural. Por se tratarem de povos 'menos evoluídos' na escala da civilização, não só estaria justificado o despotismo inglês nos assuntos internos sem a necessidade de consentimento por parte da população, como Mill acreditava que a Inglaterra tinha como obrigação moral intervir de modo a aperfeiçoá-los. E na sua prática como homem público, principalmente no

(26) Para uma descrição detalhada das tarefas exercidas por Mill na Companhia das Índias, ver Moir (1990). 
que concerne aos seus posicionamentos em relação à Índia e à Irlanda, Mill manteve-se fiel à idéia de que a intervenção despótica da Inglaterra (ou de qualquer outro país 'avançado') só poderia ser aceita caso levasse a um aprimoramento dos povos subjugados, preparando o caminho para o autogoverno. $^{27}$

Explicita também a importância que o aprimoramento humano assume na sua filosofia social. ${ }^{28}$ A forma de governo e a atuação do Estado deveriam ser distintas em diferentes sociedades, mas o critério básico de escolha e de avaliação destas era, tanto no caso das sociedades 'desenvolvidas' como das 'atrasadas', o seu impacto positivo (no longo prazo) sobre o intelecto e a moralidade da população. E tornar os homens melhores significava, em última instância, desenvolver as suas capacidades ativas: a autonomia, a energia de caráter, a capacidade de discernimento, o autocontrole, as afetividades sociais, a capacidade de escolha, e assim por diante. Por conta de uma 'imaturidade' intelectual e moral, alguns povos precisariam ter, temporariamente, como guias governos paternalistas ou despóticos e ter na figura do Estado o grande provedor de suas necessidades. No entanto, a função primordial do Estado (doméstico ou estrangeiro) deveria ser 'preparar' os homens para serem capazes de se autogovernar e de proverem através de suas iniciativas (individuais ou coletivas) os bens e serviços essenciais à sociedade. ${ }^{29}$ Como Mill coloca, “(...) fios-condutores (leading-strings) só são admissíveis como um meio de treinar gradualmente as pessoas a andarem sozinhas" (Mill, [1861], 1958, p. 332-333).

Assim, apesar de não serem adequadas a todas as sociedades, a Democracia Representativa e o laissez-faire têm uma importância na filosofia social de Mill como ideais a serem buscados. Quando todos os povos atingissem através, entre outras coisas, da atuação do Estado - a 'maturidade' (ou 'maioridade') moral e intelectual necessárias para fazer bom uso da liberdade, essas instituições, até então restritas a uma pequena parcela do globo, deveriam prevalecer sobre toda a sua extensão para garantir a continuidade do progresso social.

\section{Referências bibliográficas}

COLLISON BLACK, R. D. Economic policy in Ireland and India in the time of John Stuart Mill. The Economic History Review, New Series, v. 21, n. 2, p. 321-336, 1968.

(27 Para uma análise sobre as políticas defendidas por Mill para a Índia, ver Moir (1990, p. xlii-liv), Harris ([1964], 1991) e Schweinitz (1984). Para análises sobre as políticas defendidas por Mill para a Irlanda, Zastoupil (1983), Hamburger (1982, p. xlix-liii) e Collison Black (1953).

(28) Ver Robson (1968) e Mattos (1998).

(29) Como aponta Miller, para Mill, “(...) mesmo 'bárbaros’ têm o direito a um tratamento que irá tornálos aptos à liberdade no momento mais próximo possível” (Miller, 1961, p. 508-509). 
COLLISON BLACK, R. D. The classical economists and the Irish problem. Oxford Economic Papers, New Series, v. 5, n. 1, p. 26-40, 1953.

EKELUND JR., R. B.; TOLLISON, R. D. The new political economy of J. S. Mill: the means to social justice. The Canadian Journal of Economics, v. 9, n. 2, p. 213-231, 1976.

J. S. Mill's new political economy: another view. Originally published in Economic Inquiry, v. 16 n. 4, p. 587-592, Oct. 1978. Reprinted in J. S. Mill: critical assessments, ed. by J. C. Cunnighan Wood. London: Routledge, 1991. v. III.

HAMBURGER, J. Introduction. In: ROBSON, J. M. (Ed.). Collected works of John Stuart Mill. Toronto and London University of Toronto Press and Routledge \& Kegan Paul, 1982. p.viii- liv, v. VI: Essays on England, Ireland and the Empire.

HARRIS, A. L. John Stuart Mill: servant of the East India company. Cambridge Journal of Economics, v. 30, May 1964. Reprinted in J. S. Mill: critical assessments, ed. by J. C. Cunnighan Wood. London: Routledge, 1991. p. 207-225.

John Stuart Mill's theory of progress. Ethics an International Journal of Social, Political, and Legal Philosophy, v. LXVI , n. 3, 1956.

HOLLOWAY, H. Mill and the welfare state. The Western Political Quarterly, v. 13 n. 2, Jun. 1960, p. 389-405.

KURER, O. John Stuart Mill and the welfare state. History of Political Economy (HOPE), v. 23, n. 4, p. 713-730, 1991.

LEVY, D.; PEART, S. A disciple without sympathy: from median to mean well-being in economic analysis. 2003. Disponível em: $<$ http://homepages.bw.edu/ speart/median_Imagesabstract_cje.pdf $>$.

MATTOS, L. V. Economia política e mudança social: a filosofia econômica de John Stuart Mill. São Paulo: Edusp, 1998.

MILL, J. S. [1834]. Remarks on Bentham's philosophy. In: Collected works of John Stuart Mill. Toronto: University of Toronto Press, 1969. v. X.

[1836]. Civilization. In: Essays on politics and culture: John Stuart Mill, ed. by Gertrude Himmelfarb, Peter Smith, Gloucester, 1973.

. [1848]. Principles of political economy with some of their applications to social philosophy. In: Collected works of John Stuart Mill. Toronto: University of Toronto Press, 1965. v. II, III.

[ [1859]. A few words on non-intervention. In: Essays on politics and culture:

John Stuart Mill, ed. by Gertrude Himmelfarb, Peter Smith, Gloucester, 1973.

. [1859]. A liberdade. In: A LIBERDADE; utilitarismo: John Stuart Mill. Trad. Eunice Ostrensky. São Paulo: Martins Fontes, 2000.

[1861]. Considerations on representative government. New York: The Liberal Arts Press, 1958.

. [1865]. August Comte and positivism. In: Collected works of John Stuart Mill. Toronto: University of Toronto Press, 1969. v. X. 
MILL, J. S. [1870]. Leslie on the land question. In: Essays on economics and society, 1850-1879. In: Collected works of John Stuart Mill. Toronto: University of Toronto Press, 1967.

MILLER, K. E. John Stuart Mill's theory of international relations. Journal of the History of Ideas, v. 22, n. 4, p. 493-514, 1961.

MOIR, M. Introduction. In: Collected works of John Stuart Mill. Ed. by J. M. Robson, Martin Moir and Zawahir Moir. Routledge, Toronto and London: University of Toronto Press, 1990. p. vii-iv, v. XXX: Writings on India.

SCHWARTZ, P. La nueva economia politica de John Stuart Mill. Madrid: Tecnos, 1968.

SCHWEINITZ JR., K. John Stuart Mill and India. Research in the History of Economic Thought and Methodology, v. 2, p. 47-61, 1984.

SULLIVAN, E. P. Liberalism and imperialism: J. S. Mill's defense of the British Empire. Journal of the History of Ideas, v. 44, n. 4, p. 599-617, 1983.

WEST, E. G. J. S. Mill's redistribution policy: new political economy or old?. Originally published in Economic Inquiry, v. 16, n. 4, p. 570-586, Oct. 1978. Reprinted in J. S. Mill: critical assessments, ed. by J. C. Cunnighan Wood. Routledge, London, 1991. v. III.

ZASTOUPIL, L. Moral government: J. S. Mill on Ireland. Historical Journal, v. 26, n. 3, p. 707-717, 1983. 